
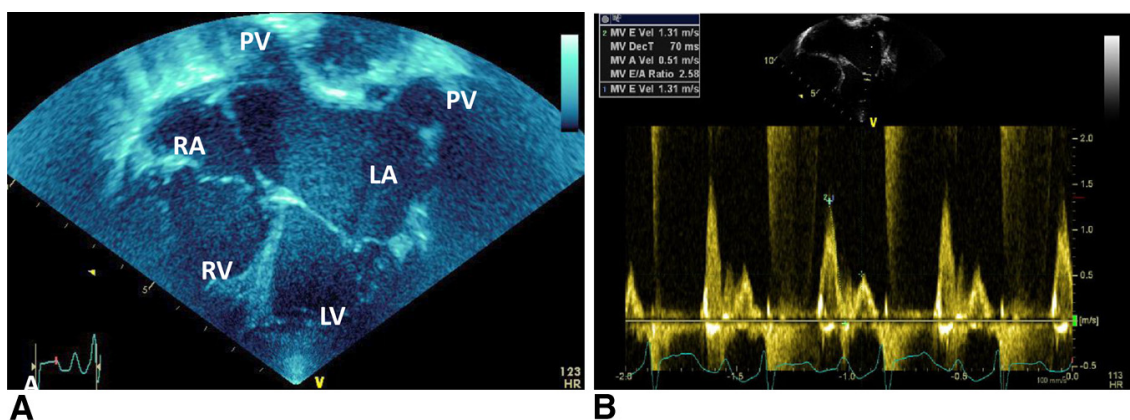

FIGURE 1. Echocardiographic studies of patient 1 with left ventricular $(L V)$ noncompaction cardiomyopathy before left ventricular assist device implantation. A, Apical 4-chamber demonstrating severe left atrial $(L A)$ dilation and pulmonary vein $(P V)$ congestion. B, Mitral inflow Doppler trace with short deceleration time. $R A$, Right atrium; $R V$, right ventricle; $M V$, mitral valve; $E$ Vel, peak E wave velocity; $D e c T$, deceleration time; $A$ Vel, peak A wave velocity; E/A ratio, ratio of peak $E$ wave velocity to peak A wave velocity.

We describe the successful use of a new $15-\mathrm{mL}$ EXCOR pump in 2 children whose requirements fell between the ideal fill and flow characteristics of the existing pumps. In children with a body surface area ranging from 0.33 to $0.55 \mathrm{~m}^{2}$ and weight ranging from 7 to $12 \mathrm{~kg}$, the $15-\mathrm{mL}$ chamber complements the EXCOR infant range. It can achieve a CI of 2.7 to $3.3 \mathrm{~L} / \mathrm{min} / \mathrm{m}^{2}$ at pump rates of 60 to 120 beats/min.

Restrictive and noncompaction cardiomyopathies are rare but contribute disproportionately to mortality in children with cardiomyopathy. ${ }^{2,3,5}$ Conventional VAD cannulation of the noncompliant LV often results in insufficient drainage, with concomitant poor pump performance, and residual LA hypertension, with subsequent pulmonary congestion. In these patients, the LA/LV disproportion with preservation of systolic function makes LA cannulation an attractive option, perhaps with less risk of ventricular thrombus formation than in dilated cardiomyopathies.
Optimal pump sizing could aid an uninterrupted drainage, and these patients could benefit most from the versatility offered by the additional chamber size.

\section{References}

1. Fraser CD Jr, Jaquiss RD, Rosenthal DN, Humpl T, Canter CE, Blackstone EH, et al. Prospective trial of a pediatric ventricular assist device. $N$ Engl J Med. 2012;367:532-41

2. Cassidy J, Dominguez T, Haynes S, Burch M, Kirk R, Hoskote A, et al. A longer waiting game: bridging children to heart transplant with the Berlin Heart EXCOR device-the United Kingdom experience. J Heart Lung Transplant. 2013;32: 1101-6.

3. Almond CS, Morales DL, Blackstone EH, Turrentine MW, Imamura M, Massicotte MP, et al. Berlin Heart EXCOR pediatric ventricular assist device for bridge to heart transplantation in US children. Circulation. 2013;127:1702-11.

4. Husain SA, Wallis G, Fricker FJ, Bleiweis MS, Staples ED, Klodell CT, et al. Ventricular assist device implantation in the pediatric population: does pump size selection and associated hemodynamics impact outcomes? ASAIO J. 2008; 54:474-8.

5. Zangwill SD, Naftel D, L'Ecuyer T, Rosenthal D, Robinson B, Kirklin JK, et al. Outcomes of children with restrictive cardiomyopathy listed for heart transplant: a multi-institutional study. J Heart Lung Transplant. 2009;28:1335-40.

\title{
Avoidance of completion pneumonectomy by sparing the right middle lobe
}

\author{
Thomas Fabian, MD, FCCP, and Jeremy W. Docekal, MD, Albany, NY
}

\footnotetext{
From the Albany Medical Center, Albany, NY.

Disclosures: Thomas Fabian reports consulting and lecture fees from Covidien. The other author has nothing to disclose with regard to commercial support.

Received for publication July 22, 2013; revisions received Feb 27, 2014; accepted for publication March 3, 2014; available ahead of print April 1, 2014.

Address for reprints: Thomas Fabian, MD, FCCP, Albany Medical Center, 50 New Scotland Ave, mc-1548290455, Albany, NY 12208 (E-mail: FabianT@mail.amc. edu).

J Thorac Cardiovasc Surg 2014;147:e80-2

$0022-5223 / \$ 36.00$

Copyright (c) 2014 by The American Association for Thoracic Surgery

http://dx.doi.org/10.1016/j.jtcvs.2014.03.004
}

Metachronous primary lung cancers (MPLCs) are defined as separate, unrelated lung cancers occurring at different times. Surgical resection remains a viable treatment option for patients with MPLCs. In patients with a history of lobectomy for the earlier ipsilateral MPLC, an additional lobectomy creates the perceived need for a completion pneumonectomy. On the right side, sparing the right middle lobe by itself is considered inappropriate by most. We challenged this common principle in treating a relatively high-risk patient. 


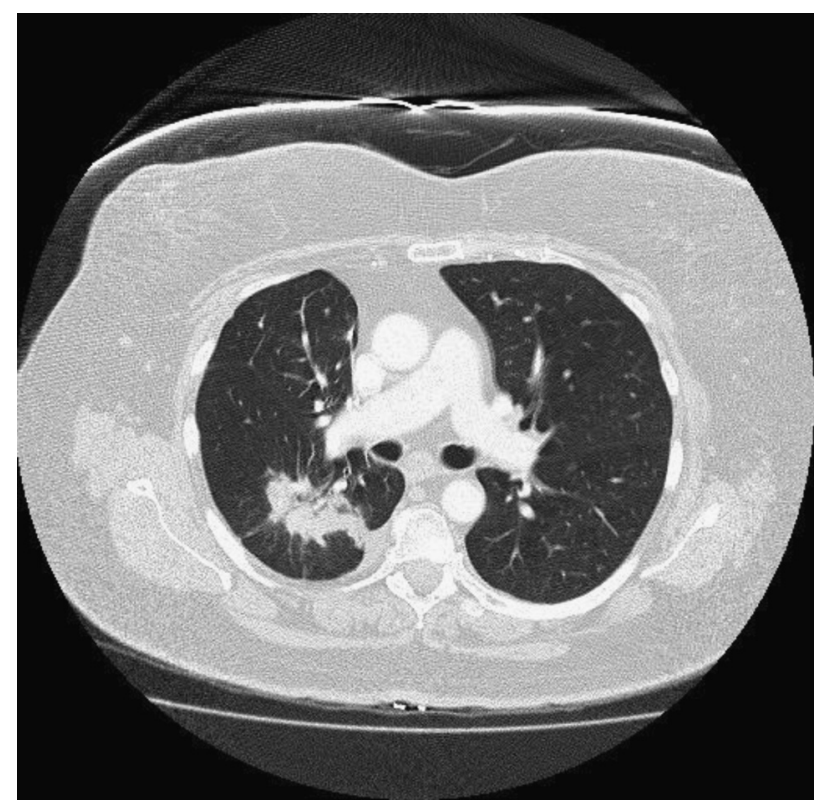

FIGURE 1. A preoperative computed tomographic scan demonstrates the $4.3-\mathrm{cm}$ metachronous primary lung cancer mass contained in the right lower lobe. The major fissure is visible.

\section{CLINICAL SUMMARY}

We report the case of a 66-year-old woman with a history of previous right upper lobectomy performed for a T2 N0 MX squamous cell carcinoma. On routine surveillance computed tomography 26 months after her first surgical resection, a $4 \times 3$-cm mass was identified in the right lower lobe (Figure 1). The mass was subsequently biopsied, and a diagnosis of a metachronous adenocarcinoma was made.

The patient reported a chronic nonproductive cough and dyspnea on mild exertion, with an Eastern Cooperative Oncology Group performance status of 2. She had recovered from her right upper lobectomy uneventfully but did require supplemental oxygen for 6 weeks after that surgery. The surgeon who performed her original right upper lobectomy considered the patient at too high a risk to undergo surgical resection, and the patient was referred to our institution for a second opinion. Pulmonary function testing demonstrated a forced vital capacity of $2.31 \mathrm{~L}(71 \%$ of predicted value), a forced expiratory volume in 1 second $\left(\mathrm{FEV}_{1}\right)$ of $1.48 \mathrm{~L}(58 \%$ of predicted value), and a ratio of $\mathrm{FEV}_{1}$ to $\mathrm{FVC}$ of $64.02 \%$ ( $82 \%$ of predicted value). A quantitative ventilation perfusion scan demonstrated perfusions of $41 \%$ and $59 \%$ to the left and right sides, respectively. The predicted postoperative $\mathrm{FEV}_{1}$ after completion pneumonectomy was $0.87 \mathrm{~L}$. The patient underwent bronchoscopy and cervical mediastinoscopy, with negative findings for N2 disease. Her clinical stage was T2 N0 M0.

The patient underwent a rethoracotomy through the site of her previous right posterolateral thoracotomy. The tumor was limited to the right lower lobe, and a formal right lower

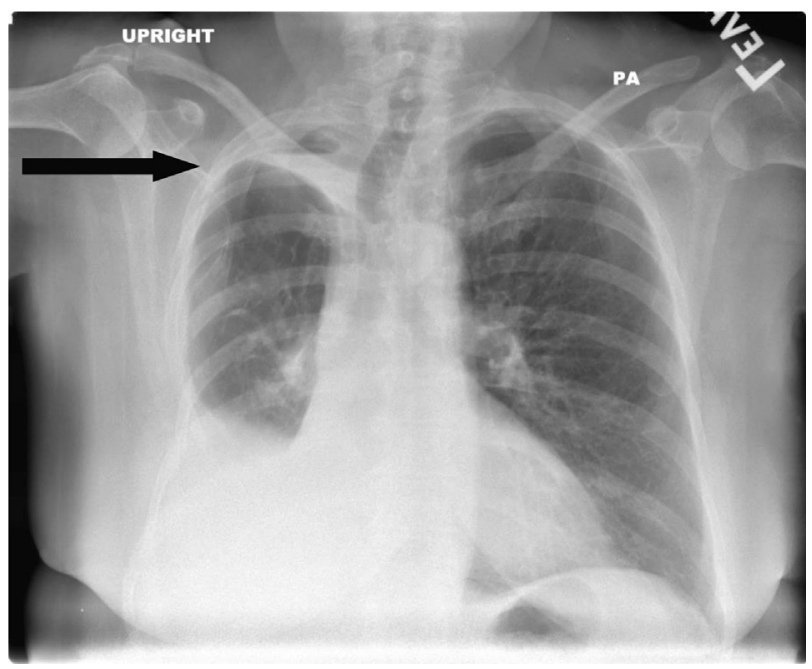

FIGURE 2. A chest radiograph taken at 3 postoperative months demonstrates the volume of the right middle lobe. The arrow marks the apical space. $P A$, Posteroanterior.

lobectomy was performed. The right middle lobe appeared grossly healthy and relatively large, with an estimated volume greater than $400 \mathrm{~mL}$. The patient's chest tubes were removed on days 3 and 4, although the postoperative course was complicated by transient atrial fibrillation, which resulted in 3 additional hospital days. The patient was discharged on postoperative day 7 without the need for supplemental oxygen. A small residual apical space was persistent at 3 months (Figure 2). Postoperative pathologic examination confirmed a $4.3-\mathrm{cm}$ right lower lobe adenocarcinoma with negative margins (pathologic stage T2a N0 Mx, stage IB). Results of pulmonary function tests performed 9 months postoperatively were nearly identical to those of preoperative testing, with the $\mathrm{FEV}_{1}$ 1.40 ( $57 \%$ of predicted).

\section{DISCUSSION}

The surgical treatment for metachronous second primary lung cancers depends on the extent of the initial surgical intervention and the patient's functional status, comorbidities, and pulmonary reserve. ${ }^{1,2}$ In the case of an ipsilateral MPLC in a patient with a previous lobectomy, the standard accepted procedure is a completion pneumonectomy. ${ }^{1-4}$

This case demonstrates that, in a select patient population, it is possible to spare the middle lobe and avoid completion pneumonectomy. This patient's mass allowed complete oncologic resection by removing the right lower lobe. Retaining the right middle lobe was thought feasible because of adhesions from the first surgery, minimizing the risk of torsion. A residual apical air space occurred postoperatively where the middle lobe was dissected to expose the R2 and R4 nodes for mediastinal dissection. 
Although this space did not result in any complications, it is the opinion of the surgeon (T.F.) that in hindsight it might have been reasonable to forego the mediastinal dissection. In this case a mediastinoscopy had been performed preoperatively, and avoiding lymphadenectomy would have eliminated the risks associated with this postoperative space. Unlike a primary resection, in which resection of the upper and lower lobes would place the middle lobe at significant risk of torsion in a reoperation, adhesions encountered in the second operation appear to reduce this risk. Iwata and colleagues ${ }^{5}$ reported a similar clinical scenario occurring on the left side, where a recurrent tumor was treated with segmentectomy to avoid completion pneumonectomy. This approach is appealing, because surgical mortality after completion pneumonectomy is reported as $20 \%$ for the right lung and $10 \%$ for the left. ${ }^{3}$

In light of this patient's limited pulmonary reserve, her oxygen requirements after her original lobectomy, and the high mortality associated with completion right pneumonectomy, ${ }^{3}$ we chose to save the middle lobe. We are unable to identify any citation stating that this approach is contraindicated. From many conversations with peers, however, most thoracic surgeons appear to believe that preserving the middle lobe by itself is in fact contraindicated or at least unwise. In the absence of evidence-based citations, reports to prove or disprove this approach are of value.

This single case report does not represent proof that this was the appropriate treatment. It may, however, stimulate interest and lead to further evaluation to support or refute this approach.

\section{References}

1. Adebonojo SA, Moritz DM, Danby CA. The results of modern surgical therapy for multiple primary lung cancers. Chest. 1997;112:693-701.

2. Fabian T, Bryant AS, Mouhlas AL, Federico JA, Cerfolio RJ. Survival after resection of synchronous non-small cell lung cancer. J Thorac Cardiovasc Surg. 2011;142:547-53.

3. Guggino G, Doddoli C, Barlesi F, Acri P, Chetaille B, Thomas P, et al. Completion pneumonectomy in cancer patients: experience with 55 cases. Eur J Cardiothorac Surg. 2004;25:449-55.

4. Angeletti CA, Mussi A, Janni A, Lucchi M, Ribechini A, Chella A, et al. Second primary lung cancer and relapse: treatment and follow-up. Eur J Cardiothorac Surg. 1995;9:607-11.

5. Iwata H, Shirahashi K, Mizuno Y, Matsui M, Yamamoto H, Takemura H. Left lower apical segmentectomy after video-assisted left upper lobectomy for relapse in lung cancer: benefit to avoid completion pneumonectomy. Gen Thorac Cardiovasc Surg. 2013;61:359-61

\title{
Extracorporeal membrane oxygenation as a bridge to surgery for ischemic papillary muscle rupture
}

\author{
Benjamin Obadia, JD, Alexis Théron, MD, Vlad Gariboldi, MD, and Frederic Collart, MD, Marseille, \\ France
}

\section{VICS Video clip is available online.}

For patients in highly unstable condition, a mobile remote cardiac assist unit (MRCAU) was created in our institution to allow implantation of an extracorporeal membrane oxygenation (ECMO) system while the patient is in a peripheral hospital, before refractory multiorgan failure

From the Department of Cardiac Surgery, La Timone Hospital, Marseille, France. Disclosures: Authors have nothing to disclose with regard to commercial support. B.O. and A.T. contributed equally.

Received for publication Dec 9, 2013; revisions received Feb 1, 2014; accepted for publication March 3, 2014; available ahead of print March 26, 2014.

Address for reprints: Alexis Théron, MD, Department of Cardiac Surgery, La Timone Hospital, 264 Rue Saint Pierre, 13385 Marseille Cedex 05, France (E-mail: alexis. theron@ap-hm.fr).

J Thorac Cardiovasc Surg 2014;147:e82-4

$0022-5223 / \$ 36.00$

Copyright (c) 2014 by The American Association for Thoracic Surgery

http://dx.doi.org/10.1016/j.jtcvs.2014.03.003 occurs. ${ }^{1}$ We report the successful treatment of a complete posteromedial papillary muscle rupture complicating an inferior ST-segment elevation myocardial infarction supported by percutaneous ECMO implantation as a bridge to surgery.

\section{CLINICAL SUMMARY}

A 67-year-old man with a history of hypertension called emergency medical services for brutal chest pain and breathlessness. At the emergency unit arrival, he was in acute respiratory failure with cardiogenic shock. He was immediately intubated and brought back to the intensive care unit. At admission, physical examination revealed an unknown $4 / 6$ holosystolic murmur at the apex and significant bilateral rales. Electrocardiography showed an ST-segment elevation in leads II, III, and aVF, suggesting an inferior ST-segment elevation myocardial infarction. Chest radiography revealed an acute pulmonary edema and ruled out left ventricular and left atrial dilatation (Figure 1). Transthoracic echocardiography revealed 